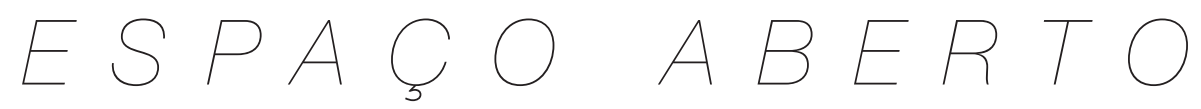

\title{
A ARTE DE APOSENTAR-SE: programa de preparação para aposentadoria com policiais federais
}

Dulce Helena Penna Soares ${ }^{1}$

lúri Novaes Luna²

Marilaine Bittencourt de Freitas Lima3

resumo

O avanço da ciência e tecnologia tem levado a um progressivo aumento da longevidade e da expectativa de vida, proporcionando aos indivíduos usufruírem um tempo maior de suas existências como aposentados ainda gozando de boas condições físicas e mentais. Sendo assim, este artigo apresenta reflexões sobre o tema aposentadoria com base no relato do Programa Preparação para Aposentadoria (PPA), desenvolvido com Policiais Federais. O Programa foi realizado em três encontros, de oito horas cada, e carac-

\footnotetext{
1 Coordenadora do LIOP (Laboratório de Informação e Orientação Profissional) e Professora do Departamento de Psicologia e do Programa de Pós-Graduação em Psicologia da Universidade Federal de Santa Catarina. Doutora em Psicologia Clínica na França. Bolsista Produtividade CNPQ. E-mail: dulce@cfh.ufsc.br.

2 Coordenador do NPTS (Núcleo de Pesquisa Trabalho e Subjetividade) e do Projeto de Extensão Identidade Profissional da UNISUL (Universidade do Sul de Santa Catarina). Professor do Curso de Psicologia da UNISUL. Doutor em Sociologia Política pela Universidade Federal de Santa Catarina. E-mail: inluna@oletelecom.com.br.

3 Graduada em Psicologia pela Universidade do Sul de Santa Catarina. Mestre em Psicologia Social (Universidade Federal de Santa Catarina). Especialista clínica em Gestalterapia (Instituto Müller \& Granzotto). E-mail: marilainepsi@yahoo.com.br .
} 
terizou-se por abordar o assunto de forma vivencial, com a utilização de técnicas específicas para trabalhar temas como projetos de vida e reorientação profissional, considerando os diferentes aspectos que permeiam este momento de mudança (saúde, lazer, finanças, espiritualidade, família, etc). Constatou-se, tanto na teoria quanto na prática, que o processo de aposentadoria dos Policiais Federais envolve mudanças específicas que requerem reorganização familiar, afetiva e social, o que evidencia a importância do desenvolvimento de programas que trabalhem estes aspectos.

palavras-chave

Aposentadoria. Programa de Preparação para Aposentadoria.

Policiais Federais.

\section{Um Olhar Sobre o Trabalho e a Aposentadoria de Policiais Federais}

Tendo em vista que o contingente de aposentados tende a ocupar uma parcela cada vez maior da população brasileira, observa-se a geração de uma crescente demanda na produção de conhecimento científico sobre essa realidade.Tal fato justifica o incremento do interesse de diversas áreas da ciência na produção de estudos e reflexões sobre o tema.

Essa realidade é facilmente constatada em nosso país, onde se identifica uma elevação significativa do percentual de aposentados nos últimos anos. Em 2002 as pessoas com mais de 60 anos representavam 9,3\% da população brasileira; atualmente (2008) estão em torno de 10,5\% e, conforme projeções, em 2020 representarão 11,4\% do total de brasileiros. Destaca-se o fato de que o crescimento relativo deste segmento, entre 1997 e 2007, foi maior do que o dobro do crescimento da população total. A Organização Mundial de Saúde (OMS) prevê que até 2025 o Brasil será o sexto maior país do mundo em número de idosos (INSTITUTO BRASILEIRO DE GEOGRAFIA E ESTATÍSTICA, 2008).

A Psicologia aparece com destaque nesse cenário, na medida em que busca conhecer diferentes aspectos do processo de aposentadoria e possibilidades de propor estratégias para modificá-lo com vistas à obtenção de uma melhora na qualidade de vida dos envolvidos (ZANELLI; SILVA; SOARES, 2010; FRANÇA, 2008; RODRIGUES et al., 2005; ZANELLI; SILVA, 1996). A atualidade, relevância e crescimento do tema ensejaram a realização do I Congresso Brasileiro de Orientação para Aposentadoria nas Organizações, 
em abril de 2010, no qual foram debatidos diferentes aspectos relacionados à carreira e aposentadoria e apresentados relatos de práticas de Programas de Preparação para Aposentadoria (PPA), desenvolvidos no Brasil, tais como as experiências do Serviço Social da Indústria de Santa Catarina (SESI/SC), da ELETROSUL Centrais Elétricas S.A. e da Polícia Militar da Bahia (UNIVERSIDADE FEDERAL DE SANTA CATARINA; INSTITUTO SAÚDE E PRODUTIVIDADE, 2010). Dentro desse contexto, o presente artigo apresenta reflexões sobre as temáticas, trabalho e aposentadoria, e a experiência prática-metodológica de um PPA denominado A Arte de Aposentar-se, desenvolvido com servidores públicos do Departamento de Polícia Federal.

Inicialmente fez-se uma revisão da literatura pertinente, onde se constatou uma lacuna de conhecimentos científicos sobre a temática "Policiais Federais e aposentadoria". Efetuou-se uma busca nas bases eletrônicas da Coordenação de Aperfeiçoamento de Pessoal de Nível Superior (CAPES) , a fim de verificar teses/dissertações relacionadas a este tema. Ao combinar os descritores, "Policial Federal e aposentadoria", não houve nenhum retorno.

Ao utilizar a palavra-chave "Policial Federal", obteve-se um total de oitenta e três pesquisas (teses/dissertações). No entanto, apenas duas se referiam a esse grupo específico (Policiais Federais). Beaklini (2004) fez um estudo sobre as atribuições da Policia Federal e a Constituição de 1988. Ely (2007) na dissertação O super-herói (nem tanto) também adoece: um estudo em saúde do trabalhador com servidores da Polícia Federal em Santa Catarina investigou questões relacionadas à saúde (física/psíquica) desses profissionais. Os outros oitenta e um trabalhos se referiam, na maioria das vezes, a policiais civis e militares, com temáticas voltadas, principalmente, aos aspectos da atividade profissional em si e a políticas de segurança pública.

Posteriormente, utilizando-se o mesmo descritor acima citado, fez-se uma busca nas bases de dados Scielo e PEPsic a fim de verificar artigos relacionados a este tema. Como resultado constatou-se não haver nenhum retorno.

Para compreender o processo de aposentadoria é necessário relacionálo ao papel central assumido pelo trabalho na vida do homem, seja na sua condição de meio de satisfação das necessidades econômicas ou na sua conotação ontológica. Nas sociedades humanas o trabalho (ou sua ausência) repercute diretamente nas relações sociais nas quais o indivíduo está envolvido, não dizendo respeito somente à aquisição de renda, mas também à forma de se relacionar com o meio. Quando o indivíduo, por qualquer motivo, afasta-se por um período relativamente longo ou definitivo de suas atividades profissionais espera-se, como consequência, uma transformação nas suas 
relações sociais e no seu modo de se relacionar com o tempo, agora supostamente livre.

Laffin (2002) considera trabalho todas as atividades realizadas pelo homem que possibilitam a ampliação da sua condição humana, capazes de satisfazer suas necessidades. O emprego, por sua vez, é o reconhecimento legal de um vínculo entre empregado e empregador. Singer (2003, p.12) sintetiza que "o emprego resulta de um contrato pelo qual o empregador compra a força de trabalho ou a capacidade de produzir do empregado [...]". Em muitos casos, pode-se assim dizer que as pessoas se aposentam do emprego e não do trabalho.

Frigotto (2002) chama a atenção para duas faces predominantes do trabalho no "novo" capitalismo: a econômica, que se refere à relação existente entre o modelo de trabalho assumido no capitalismo na forma de trabalho assalariado (ou na forma de emprego), e a ontológica, reconhecida como fonte criadora da existência humana, inerente a sua condição. Essas duas formas de compreender o trabalho podem suscitar uma confusão conceitual. Como exemplo, o autor cita um diagnóstico no qual mais de $90 \%$ das donas de casas de um bairro popular, quando questionadas se trabalhavam, responderam que não. Esse resultado mostra que, na maioria das vezes, o trabalho é reconhecido no senso comum apenas pela sua conotação econômica. Nesse sentido, a aposentadoria é entendida como a passagem de uma vida de trabalho para ausência deste.

Seja como meio de garantir a subsistência, como forma de realização pessoal, como regulador da organização da vida humana, seja como "mal necessário" ou como fonte de satisfação, reconhece-se que o trabalho ocupa a maior parte do tempo em que vivemos e se configura como referência central no processo de construção da identidade pessoal. Emergindo das interações do indivíduo com a sociedade, de forma ampla, e com as organizações de trabalho, de forma específica, a identidade profissional estrutura-se como "resposta às perguntas: O que faço? Onde? Como? Com quem? Para quem? Quando? Para que (futuro, projeto)? Por que (passado, história)?" (LUNA; BAPTISTA, 2001, p. 49); deste modo, relaciona-se diretamente com a cultura organizacional e com a Qualidade de Vida no Trabalho (TOLFO; SILVA; LUNA, 2009). O processo de aposentadoria, ao transformar a autopercepção e a percepção de outrem a respeito do indivíduo, produz um forte impacto sobre a identidade profissional e, por conseguinte, sobre a identidade pessoal.

Entre os sinônimos para o verbo "aposentar", Zanelli e Silva (1996) apresentam o que consideram mais estarrecedor: "pôr de parte, de lado"; significa 
uma exclusão que a sociedade impõe àqueles que chegam ao final da carreira: se não trabalham mais, deixam de ser importantes. A posição de Soares e Costa (2008 p.38) é semelhante: "Ser aposentados é deixar de ser João, o professor; Maria a enfermeira; José o médico... Serão todos simplesmente João, Maria e José, os aposentados ou de forma depreciativa, os inativos.".

Em relação à aposentadoria, não se pode deixar de pensar em uma mudança real e concreta na vida do indivíduo. Moscovici (2000) apresenta dois cenários distintos no final de carreira: o primeiro diz respeito a uma pessoa satisfeita com os resultados profissionais alcançados até o momento, porém há uma preocupação com o pouco tempo que sobra para alcançar mais, levando a pensar na aposentadoria como algo limitador e desagradável. O segundo se refere a um profissional que considerava o seu trabalho seguro e estável, e com a chegada da aposentadoria, faz uma avaliação da sua carreira, percebe que não era esta a vida desejada, porém acha que não há mais tempo para mudar. Esse sentimento pode levar a uma crise existencial e, em alguns casos, até mesmo à depressão.

A aposentadoria é um período de se encarar o mundo do não trabalho assalariado. Este mundo é totalmente novo e o momento requer uma reorganização da vida familiar, novas relações afetivas, novos espaços de convívio e relacionamentos fora do mundo do trabalho, novas rotinas e até a diminuição gradativa da jornada diária. Como possibilidades, surgem os trabalhos alternativos, hobbies, as experiências em artes e ofícios que geram autonomia em relação à organização do tempo em função do trabalho (CARLOS et al., 1999). Não obstante, o tempo livre na aposentadoria pode ser vivenciado de modo ambivalente: ser usado para o desenvolvimento pessoal, mas também experimentado como um tempo sem sentido. Assim, é importante o desenvolvimento de um ócio maduro nesta fase da vida; entretanto, poucas pessoas desenvolvem práticas que possibilitem o uso do tempo livre que as satisfaçam (CABEZA, 2009).

Destarte, evidencia-se a importância dos Programas de Preparação para Aposentadoria, tanto no âmbito público quanto no privado, pois a aposentadoria, de modo semelhante a outras mudanças significativas, como a primeira inserção no mundo do trabalho e vivências de desemprego, pode ser um fato gerador de estresse, angústia, ansiedade e desencadear desequilíbrios, não só daqueles que se aposentam, mas de todas as pessoas que fazem parte deste ciclo. Trata-se de um processo que abre novas oportunidades de vida que podem ser percebidas e vivenciadas de diferentes formas por todos os envolvidos. 
A Carreira Policial, objeto deste estudo, está dividida em cinco cargos: Agente de Polícia Federal (APF), Perito Criminal Federal (PCF), Delegado de Polícia Federal (DPF), Papiloscopista Policial Federal (PPF) e Escrivão de Polícia Federal (EPF). O ingresso se dá por concurso público em duas fases, com a realização de Curso de Formação Profissional (eliminatório) na Academia Nacional de Polícia (Brasília/DF), na segunda fase, para os aprovados na primeira fase (ELY, 2007).

A jornada de trabalho dos Policiais Federais é de 40 horas semanais ou em regime de plantão de 24 horas trabalhadas por 72 horas de descanso, com dedicação exclusiva e tempo integral. Isto significa que os servidores não podem exercer outra atividade remunerada (com exceção dos casos previstos na legislação) e que podem ser convocados a qualquer momento (DEPARTAMENTO DE POLÍCIA FEDERAL, 2004).

Ser Policial Federal exige obediência a um conjunto de princípios e valores ético-morais, explicitados no juramento, assumidos em declaração solene perante a sociedade, no momento da posse: "Juro, pela minha honra, que envidarei todos os meus esforços no cumprimento dos deveres do Policial Federal, exercendo minha função com probidade e denodo, se necessário, com sacrifício da própria vida" (DEPARTAMENTO DE POLÍCIA FEDERAL, 2004).

Para ser policial não basta o uso da arma, da carteira funcional ou do uniforme, embora se trate de símbolos de forte significação. Esse profissional deve ter atitudes, condutas e comportamentos pautados pelo respeito à ética, com a preocupação de investir permanentemente numa profissão que busca garantir segurança e tranqüilidade para a sociedade (DEPARTAMENTO DE POLÍCIA FEDERAL, 2004).

Além disso, o artigo 301 do Código de Processo Penal reza que "Qualquer do povo poderá e as autoridades policiais e seus agentes deverão prender quem quer que seja encontrado em flagrante delito". A conseqüência prática desse dispositivo legal é que o policial deve exercer sua função vinte e quatro horas por dia, podendo responder criminalmente em caso de omissão, mesmo fora do horário de expediente. Percebe-se assim que a identidade profissional do Policial Federal vincula-se fortemente à sua maneira de ser e estar no mundo.

Conforme anteriormente discutido, a carteira funcional e a arma de fogo, mais do que ferramentas de uso diário do profissional, são objetos que simbolizam a identidade do ser policial. Aos Policiais Federais da ativa são ainda facultadas prerrogativas diferenciadas, tais como a propriedade e o porte diu- 
turno de armamento de calibres restritos, inclusive em aeronaves. Com a aposentadoria, esse status quo sofre alterações, conforme disciplinado por normas internas do Departamento de Polícia Federal (DPF).

A esse respeito, a Instrução Normativa n 011/94 - DPF, de 10/10/1994, dispõe os casos em que a carteira funcional do servidor policial é recolhida. Entre outras situações marcantes (falecimento, demissão, exoneração) que podem originar esse evento, a aposentadoria obriga a substituição do documento por outro modelo, exclusivo de inativos. Da mesma forma, a Instrução Normativa no 005/DG, de 27/05/1988, lista os casos de recolhimento das armas do acervo do DPF concedidas aos servidores. Novamente a aposentadoria está entre eventos contundentes que obrigam o policial a devolver a arma, quase sempre de calibre de uso restrito, quando esta for patrimônio da Instituição.

Observa-se assim que objetos emblemáticos da atividade são substituídos no momento da aposentadoria. Em vez da carteira de identidade funcional "Modelo A", usada pelos servidores ativos, os aposentados, considerados inativos, passam a utilizar a carteira "Modelo B"; no lugar do fuzil, apenas podem utilizar um revólver ou pistola de calibre de uso permitido a cidadãos não policiais. Acabam as operações com uso de uniformes e viaturas ostensivas; não se tem mais acesso a ferramentas e equipamentos de última geração, usados durante o período de trabalho.

No caso específico dos policiais, as normas de aposentadoria são regidas pela Lei Complementar $n^{\circ}$ 51, de 20 de dezembro de 1985, com destaque para o artigo $1^{\circ}$ :

Art.1 ${ }^{\circ}$ - O funcionário policial será aposentado:

I - voluntariamente, com proveitos integrais, após 30 (trinta) anos de serviço, desde que conte, pelo menos 20 (vinte) anos de exercício em cargo de natureza estritamente policial;

II - compulsoriamente, com proventos proporcionais ao tempo de serviço, aos 65 anos (sessenta e cinco) anos de idade, qualquer que seja a natureza dos serviços prestados.

Assim sendo, a faixa etária em que o grupo específico se aposenta varia, na maioria das vezes, entre 48 e 55 anos de idade.

Tendo em vista as especificidades dessa categoria profissional, mencionadas anteriormente, para os Policiais Federais, transitar de um espaço produtivo para uma situação de aposentadoria possui significativas implicações no que se refere à construção de suas identidades, o que reforça a relevância do Programa que será apresentado a seguir. 
Desenvolvido por Psicólogos, A Arte de Aposentar-se é um Programa de Preparação para Aposentadoria (PPA) com envolvimento ativo dos participantes e realização de atividades práticas de grupo, com a proposta que cada indivíduo construa seu próprio processo, com criatividade, autonomia e posicionamento crítico frente ao novo cenário que se apresenta.

O Programa foi implantado no ano de 2009, num estado da região sul do Brasil, por um Sindicato de Policiais Federais. Ele foi elaborado e coordenado pelos Psicólogos responsáveis por este artigo.

Primeiramente, fez-se uma palestra de duas horas para os servidores aposentados e pré-aposentados na sede da Superintendência Regional da Policia Federal, com o objetivo de sensibilizar os participantes e expor o programa. Após, foram abertas vinte inscrições para os principais interessados, sendo todas preenchidas no ato.

O Programa teve início em junho de 2009 e foi desenvolvido num total de trinta horas (três encontros quinzenais, de oito horas cada, totalizando 24 horas de trabalho com o grupo, e seis horas de planejamento e avaliação do trabalho com os principais responsáveis). Dos vinte inscritos, compareceram ao programa quinze servidores, entre eles cinco já aposentados, cinco com tempo para se aposentar, mas que haviam decidido permanecer, e cinco aguardando o tempo para se aposentar. Para a elaboração do Programa utilizou-se como referencial o Programa de Preparação para Aposentadoria Aposenta-Ação, oferecido em uma Universidade Federal do Sul do Brasil. Por meio das atividades grupais é possível fazer reflexões, integração e troca de experiências e um planejamento de vida, a fim de prevenir os vários conflitos que podem surgir numa aposentadoria não planejada (SOARES et al., 2007).

Os objetivos desse trabalho foram prevenir possíveis problemas causados com o advento da aposentadoria, minimizar ansiedades e dúvidas comuns nesta etapa de vida, preservar o sentimento de realização e de autoestima por tudo o que os participantes conquistaram no passado e, principalmente, desenvolver projetos de vida futuros, que permitam a satisfação pessoal através de atividades planejadas a partir do reconhecimento de interesses e motivações.

A fim de atingir estes objetivos, buscou-se trabalhar por meio de atividades grupais, oito temas norteadores, descritos a seguir:

1)Auto-conhecimento; 
2)Mudanças e Escolhas;

3)Dinâmica familiar e social;

4)Saúde na aposentadoria;

5)Administração do tempo livre ;

6)Administração financeira;

7) Projetos de vida.

A descrição dos três encontros terá a seguinte sequência: inicialmente serão apresentados os objetivos norteadores do encontro específico, elaborados previamente (respeitando, porém, o desenvolvimento natural do grupo no momento da execução da técnica). A seguir, serão expostos os procedimentos realizados em cada um dos momentos nos períodos matutino e vespertino, que dizem respeito à prática das atividades das coordenadoras, com a inclusão do relato das técnicas utilizadas. Por fim, os comentários, que compreendem a organização e a descrição da fala dos participantes durante os respectivos momentos, serão apresentados.

\subsection{Primeiro Encontro:}

Objetivos: formar vínculo grupal; conhecer as expectativas dos participantes em relação ao Plano de Preparação para a Aposentadoria (PPA); realizar um diagnóstico das expectativas quanto ao futuro após a aposentadoria; trabalhar o autoconhecimento.

\section{Matutino}

\section{1momento:}

Procedimentos: inicialmente realizou-se a apresentação das coordenadoras. Na seqüência, estabeleceu-se o contrato de trabalho com o grupo, pois "nenhum trabalho psicológico pode acontecer sem estabelecimento de um contrato entre ambas as partes, psicólogo-orientador e cliente-orientando" (SOARES, 2002, p.170). Após, solicitou-se a apresentação de cada um dos participantes mediante uma característica pessoal considerada significativa no desempenho do trabalho. Esta etapa foi concluída com a aplicação da técnica "nome de índio" (LUCCHIARI-SOARES, 1992, p.43): foi solicitado aos participantes que se reunissem em quatro grupos de acordo com as características apontadas anteriormente por eles; após, cada um deveria falar sua expectativa com o grupo de PPA e dar um nome para sua tribo.

Comentários do grupo: o grupo espera do PPA mais esclarecimentos sobre a aposentadoria, mais integração entre os participantes. Como é um programa pioneiro para Policiais Federais, espera-se que tenha um resultado 
satisfatório, para que seja difundido nos outros sindicatos da categoria. As tribos e as expectativas levantadas foram as seguintes:

Tribo Xokleg: vemos a aposentadoria como um momento de conflito, mas não pode ser considerada bicho-de-sete-cabeças. (GRUPO A).

Tribo Caioás: esperamos que sejam trabalhados no PPA temas como integração, orientação, ocupação, conscientização e esclarecimentos sobre as surpresas deste momento. (GRUPO B).

Tribo Tribalistas: queremos que o curso atinja as expectativas; fale sobre as experiências de outros aposentados; ajude-nos a tomar decisões no futuro e que o Programa seja difundido para outros sindicatos. (GRUPO C).

Tribo Desobrigados: este Programa deve passar uma visão de aposentadoria ativa; abrir novos caminhos e facilitar para que o momento da aposentadoria seja de liberdade. (GRUPO D).

\section{$2^{\circ}$ momento:}

Procedimentos: mantendo-se os grupos iniciais, utilizou-se a técnica: "trevo de quatro folhas da aposentadoria" (SOARES et al., 2009), representando quatro dimensões da vida dos participantes: Lazer e Tempo Livre; Finanças; Família e Social; Saúde. A finalidade da técnica foi conhecer as expectativas, desejos e incertezas na aposentadoria nestas quatro dimensões. Cada grupo escolheu uma das dimensões para fazer uma das folhas do trevo; depois de confeccionada, o grupo fez uma apresentação aos demais participantes, sendo possível aos outros colegas acrescentarem novos conteúdos aos já apresentados. No final, o trevo ficou completo, com as quatro dimensões.

Comentários do grupo:

Lazer e Tempo Livre: desejo de aprender a tocar violão; desenvolvimento de atividades lúdicas; estabelecimento de uma rotina, porém com um fazer desobrigado; possibilidade de ler. "Aposentado não é morto." (PARTICIPANTE D).

Finanças: sinônimo de segurança e prevenção, por isso a importância de ter um imóvel, plano de saúde, seguro de vida. "Refletir sobre este momento é poder olhar e fazer escolhas." (PARTICIPANTE B); não ao imediatismo, continuar tendo responsabilidades; procurar aumentar a renda; um momento da vida no qual se tem menos obrigação no trabalho; lazer organizado, sem endividar-se; trabalhar por opção e não por obrigação. "Valorizar o ser, mais do que o ter." (PARTICIPANTE D).

Família e Social: momento de cultivar amizades antigas, pois novas amizades são difíceis; expectativa de ser bem recebido em casa. "Devemos tomar cuidado com as pessoas que vão se aproximar [...]." (PARTICIPANTE G). 
Saúde: a saúde depende da mente; prevenção; atividades físicas. "Somos aquilo que pensamos, se tivermos uma mente sadia teremos um corpo são." (PARTICIPANTE G). "Exemplo da máscara do avião: devemos cuidar de nós primeiro, depois do outro, pois ninguém dá ao outro aquilo que não tem." (PARTICIPANTE F).

\section{Vespertino}

\section{$3^{\circ}$ momento:}

Procedimentos: iniciaram-se as atividades com uma palestra sobre várias fases da vida (infância, adolescência, primeiro emprego..., vida adulta e velhice). No decorrer da palestra, após a apresentação de cada uma das fases, disponibilizou-se cinco minutos para que os participantes, em dupla, relatassem uma situação significativa referente àquela fase. Destaca-se que no final formou-se um grande grupo, ao invés de duplas.

Neste momento, percebeu-se uma sensibilização dos participantes; o grupo mostrou-se bastante integrado, compartilhando experiências significativas com todos os colegas presentes.

Comentários do grupo: é importante parar e refletir sobre estas várias fases da vida; momento de retrospectiva e balanço de tudo o que foi feito e do que se pode vir a fazer; comparativo; interessante perceber esta evolução.

\section{$4^{\circ}$ momento:}

\section{Procedimentos:}

Análise da Trajetória de Vida: após sensibilizar o grupo com a palestra descrita anteriormente, realizou-se a técnica "Gráfico da vida profissional" (SOARES, 2002). Primeiramente, cada um deveria construir sua linha da vida. Depois de elaboradas, as linhas da vida deveriam ser compartilhadas em duplas e, por fim, apresentadas pela dupla ao grande grupo. Por meio dessa técnica é possível relembrar as vivências mais marcantes, além de identificar, ao longo da vida, as escolhas realizadas e sua relação com a construção da trajetória de cada um. Por fim, a aposentadoria: o modo como cada um vive a aposentadoria é mais uma das muitas escolhas que se faz.

Comentários do grupo: momentos mais importantes do grupo: aprovação no concurso; posse no cargo de Policial Federal; apreensão de drogas; casamento; nascimento dos filhos; formatura. Para a maioria dos participantes a trajetória de vida possibilitou ver quantas conquistas importantes foram vivenciadas.

"Sinto-me um pouco perdido quando saio do plantão (tempo livre). Atualmente sou voluntário do Corpo de Bombeiros, a minha primeira escolha era ser médico, mas hoje o projeto de futuro (aposentado) é fazer enfermagem" (PARTICIPANTEN). 
"Aos 13 anos o meu sonho profissional era ser marinheiro; reprovei. Caiu o mundo, comecei a trabalhar com 14 anos, acho que o fracasso valeu a pena. Entrei no DPF, agradeço sempre pelo trabalho. Quanto me aposentei, perdi os amigos de trabalho, amigos de profissão, estou sentindo meio problemático... Não quero ficar parado, atualmente só faço atividades físicas. Já fui a agências de recolocação no mercado (área de investigação). É difícil cortar o cordão umbilical com o DPF, considero um vício, pois gostava muito do que fazia. Estou aposentado há um ano." (PARTICIPANTE F).

\section{$5^{\circ}$ momento:}

Procedimentos: para finalizar solicitou-se de cada participante uma palavra que descrevesse como se sentira durante o primeiro encontro. Outro colega deveria, então, explicar o que significara aquela palavra para ele, dizer também a sua palavra e assim sucessivamente, até que todos tivessem falado.

Comentários do grupo: este primeiro encontro superou as expectativas, foi proveitoso, objetivo e reflexivo, trazendo esperança de viver uma aposentadoria com qualidade.

Proveitoso, pelo conhecimento que trouxe. Excelente, maneira como foi dado o curso. Autêntico, debate franco e aberto, alerta para decisões. Mudanças, renovação. Esperança, construção futura. Reflexão, serviu para refletir sobre o presente e o futuro. Coragem, para tomar um novo rumo, seguir uma nova direção. Oportunidade, poucas pessoas chegam ao estágio em que nós estamos. Decisão, de estar aqui, abrindo uma oportunidade de enxergar o necessário para este momento. Conhecimento, daquilo com o que vai se deparar daqui para frente. Progresso, é o momento que o país está passando. Amor, dedicação, não sair às escuras. Objetividade, principal objetivo para refletir sobre o futuro. Futuro, é o que temos pela frente, é tudo o que se tem para ser feito, o leque de possibilidades que temos (TODOS OS PARTICIPANTES).

\subsection{Segundo Encontro}

Objetivos: auto-avaliar formas de viver atualmente nas várias dimensões (familiar, social, física, emocional, financeira, espiritual, profissional e intelectual); refletir sobre as dimensões que deixam a desejar, auxiliando na busca de possíveis mudanças; planejar o controle financeiro pessoal e familiar e a utilização do tempo livre.

\section{Matutino}

\section{$1^{\circ}$ momento:}

Procedimentos: as atividades iniciaram com a técnica "Roda da vida" (técnica adaptada e não publicada). A finalidade dessa técnica é auto-avaliar, 
de forma realista, as várias dimensões descritas nos objetivos. No final da atividade, cada participante visualizou a pontuação obtida, através de um gráfico colorido, possibilitando assim identificar o que gostaria de mudar e o que pode permanecer como está.

Comentários do grupo: essa atividade possibilitou refletir sobre como estão vivendo as diversas dimensões, o que priorizam como bem-estar e a possibilidade de promover mudanças. A seguir encontram-se os comentários sobre as diferentes dimensões discutidas:

-Familiar e Social: há um retorno ao lar; ficam mais próximos da família. Em contrapartida, o social fica um pouco prejudicado, pois uma das características do trabalho de policial é manter o sigilo, inclusive o anonimato da sua própria identidade, restringindo na maioria das vezes o vínculo de amizades fora do grupo de trabalho. Sendo assim, se aposentar é deixar de conviver com os amigos "colegas de trabalho" e buscar se inserir em novos grupos.

-Financeira: embora não tenham perda salarial, a discussão desta dimensão foi relevante para refletir sobre a importância do controle e planejamento de gastos e ganhos.

-Intelectual: refletir sobre essa dimensão levou alguns participantes a repensarem o investimento em novos estudos como graduação, curso de inglês ou mais leituras.

-Profissional: os participantes (aposentados e não aposentados) se mostraram realizados com a profissão de policial; a inserção em outro trabalho seria mais para ocupar o tempo livre.

-Física: muitos se mostraram satisfeitos com suas rotinas físicas, comuns à categoria, porém alguns se conscientizaram da importância da mudança de hábito para uma vida mais saudável.

-Emocional: algumas questões foram levantadas nessa dimensão, tais como a dificuldade de expressar os sentimentos (devido à própria profissão) e de pedir ajuda quando necessário. O trabalho grupal possibilitou essa troca, pela expressão de sentimentos e compreensão por parte do grupo.

-Espiritual: a maioria se sentiu satisfeito com o resultado desta dimensão.

Por fim, o seguinte comentário: "esta atividade foi instigante, cutucou todo mundo em coisas que nós vivemos e não mexemos, como intelectual, físico, emocional." (PARTICIPANTE O).

\section{Vespertino}

\section{$2^{\circ}$ momento:}

Procedimentos: as atividades da tarde foram retomadas com um exercício de aquecimento ao ar livre. Cada participante propôs um exercício, de- 
vendo este ser executado por todos e assim sucessivamente, até que todos os participantes tivessem proposto.

Comentários do grupo: a atividade física proporcionou ao grupo uma maior integração e descontração. Alguns perceberam que não estavam numa condição física ideal.

\section{$3^{\circ}$ momento:}

Procedimentos: para refletir sobre aspectos financeiros propôs-se a técnica "Gosto e gasto", adaptação da técnica "Gosto e faço" (LUCCHIARI-SOARES, 1992, p. 44-45), que possibilita ao participante tomar consciência das várias formas de gastos financeiros.

Comentários do grupo: a aposentadoria pressupõe um tempo mais disponível, o que acaba expondo-os mais ao consumo, por isso a importância de falar sobre este tema num PPA. "É muito importante discutir sobre o financeiro, pois ele afeta diretamente a saúde, devemos ser previdentes." (PARTICIPANTE C). A impulsividade deve ser contida; o orçamento financeiro deve ser construído com a família. "É difícil para os pais estabelecer limites, quando se tem condições financeiras, pois cada filho no seu quarto quer sua TV, computador e tudo mais." (PARTICIPANTE G).

No final dessa atividade, distribuiu-se uma planilha como sugestão para auxiliar no planejamento do orçamento doméstico.

\section{$4^{\circ}$ momento:}

Procedimentos: utilizou-se a técnica "Agenda colorida" para reflexão sobre o tempo livre. Solicitou-se que descrevessem todas as atividades feitas durante uma semana, logo após, usassem lápis colorido para diferenciar as várias atividades realizadas no dia-a-dia. Através dessa técnica é possível visualizar e repensar as atividades (trabalho ou tempo-livre) feitas ao longo da semana.

Comentários do grupo: para os que não se aposentaram, o preenchimento da agenda oportunizou reconhecer a ampla parcela de tempo que o trabalho ocupa em suas vidas. Essa tomada de consciência despertou questionamentos acerca do que será feito com esse tempo num futuro próximo. "Não sei administrar o tempo, pois sou muito perfeccionista, deixo de viver as coisas mais simples, vivo na perfeição, foi importante para mim esta reflexão." (PARTICIPANTE C). Os aposentados perceberam como estão utilizando o tempo livre: para alguns já foi possível construir uma rotina de atividades diárias, como caminhadas, leituras, inserção em sindicatos. "Ocupar o tempo é o mais importante, ler muito, caminhar... enquanto se sente que tem valor, quem faz esse valor é você mesmo. O valor somos nós que nos damos." 
(PARTICIPANTE J). Outro aposentado afirmou: "tenho vergonha de dizer que sou inativo e deixei de ser policial." (PARTICIPANTE F).

No final do segundo encontro foram solicitadas sugestões de temas para ser trabalhados no último dia do Programa. A maioria dos participantes afirmou que estava satisfeita com os temas trazidos até então; um dos participantes sugeriu às coordenadoras o relato de experiências práticas de como outros grupos vivenciam a aposentadoria.

\subsection{Terceiro Encontro}

Objetivos: elaborar um planejamento de vida com objetivos e metas a curto e longo prazos; concluir as atividades com uma avaliação crítica sobre o Programa desenvolvido.

\section{Matutino}

\section{1momento:}

Procedimentos: foi solicitado para os participantes que relatassem como se sentiam em relação ao Programa até a presente ocasião. Destaca-se que nesse momento estavam presentes na atividade os Presidentes Nacional e Estadual do Sindicato dos Policiais Federais. Acredita-se que a presença de ambos não interferiu significativamente na liberdade de expressão dos participantes do grupo.

Comentários do grupo: considerando-se ser este o último encontro, os comentários foram mais reflexivos, demonstrando um crescimento grupal. "Este grupo para mim foi uma quebra de paradigma, nos mostramos mais afetivos. Abre possibilidades de deixarmos de viver enclausurados e passarmos a viver com mais intensidade." (PARTICIPANTE A). "Foi uma ação embrionária a implantação de um programa como este na Policia Federal. Eu me sinto meio travado, enclausurado nos próprios problemas. Este curso me possibilitou compartilhar meus problemas". (PARTICIPANTE O). Pôdese também contar com a palavra do Presidente Nacional do Sindicato, tendo este demonstrado muita satisfação em estar presente no último encontro de um programa pioneiro na Policia Federal, tendo elogiado a iniciativa do atual Presidente Estadual do sindicato pela implantação deste PPA.

Para finalizar, o Presidente Nacional do Sindicato, antes de retirar-se, afirmou: "Nós, policiais ganhamos uma arma, uma carteira, somos quase um personagem, não podemos ter medo. A polícia é quase um espírito encostado em nós. A aposentadoria é nos livrar disso.".

\section{$2^{\circ}$ momento:}


Procedimentos: palestra interativa sobre Planejamento de Vida, tendo como focos principais a busca da definição de objetivos de vida (mais genéri$\cos$ ), de metas (mais específicas e quantificáveis, inclusive em relação ao tempo) e de estratégias (ações necessárias para o alcance das metas estabelecidas) e a gestão do planejamento. No final foi realizada uma atividade prática para exercitar a construção do Planejamento de Vida, com a participação de todos os integrantes do grupo. A seguir, cada um dos participantes apresentou ao grupo o planejamento realizado.

Comentários do grupo: esta palestra deu subsídios para construção de um planejamento de vida mais realista; possibilitou sair do sonho, ou seja, elaborar maneiras de alcançar os sonhos. As reflexões serviram para perceber a importância de um planejamento de vida: "Na ativa matamos dois leões por dia, como aposentados saímos à caça de leões." (PARTICIPANTE O). "A categoria de policial é a que encontra mais dificuldade para sair de ativo para inativo, pois ela não nos prepara para vivermos lá fora." (PARTICIPANTE C). "Queria fazer um curso de línguas, agora comecei a planejar os passos." (PARTICIPANTE M).

\section{Vespertino}

\section{$3^{\circ}$ momento:}

Procedimentos: palestra sobre o tema "Aposentadoria, fim ou recomeço? Percepção de professores aposentados sobre a influência da aposentadoria nas suas trajetórias profissionais e nos seus estilos de vida" (LIMA, 2006).

Comentários do grupo: é relevante saber como outras pessoas vivem este momento de aposentadoria; isso faz com que haja uma percepção de como o fenômeno pode ser semelhante para diversas categorias de profissionais, sendo que o modo como cada um se experimenta como aposentado é único. "Achei muito semelhante às experiências relatadas com as que vivemos aqui em grupo." (PARTICIPANTE G).

\section{$4^{\circ}$ momento:}

Procedimentos: Foi solicitado aos participantes que elaborassem, individualmente, um projeto de vida para aposentadoria com base na palestra do período matutino.

Comentários do grupo: construir um projeto de vida como aposentado é buscar objetivos mais simples, sem grandes aquisições materiais, por isso é muito mais um planejamento para vida que inclui: fazer o que se gosta; nova inserção no mercado de trabalho com flexibilidade de horários; continuação dos estudos; uso dos conhecimentos adquiridos durante a ativa; hora de realizar mais e idealizar menos. "Hoje os objetivos são mais simples. Aos vinte, trinta e/ou quarenta anos poderia parecer frustrantes objetivos tão simples e imediatos, mas aquela idade é o período da busca, realização profissional, 
social familiar e material. Quando chegamos à aposentadoria, teoricamente, atingimos um ponto razoável de satisfação destes itens, podendo então usufruir a 'bella vita', a qual tentaremos prolongar ao máximo." (PARTICIPANTE A).

No final do Programa solicitou-se a todos o preenchimento de uma ficha de auto- avaliação do PPA (SOARES, 2002, p.186). No Quadro 1 (anexo) encontram-se as questões propostas com uma síntese dos resultados, assim como falas selecionadas dos participantes.

\section{Resultado do Programa A Arte de Aposentar-se}

O resultado, de modo geral, confirmou o que foi apresentado na discussão teórica inicial, especialmente no que diz respeito aos seguintes tópicos: sentimentos de ambivalência vinculados às mudanças significativas causadas pela aposentadoria; alterações nas relações familiares e sociais; destaque excessivo, ao longo da vida, ao papel profissional e sentimento de desamparo no momento da aposentadoria. Quanto ao grupo específico (Policiais Federais) percebe-se o orgulho destes profissionais pela profissão exercida, advindo com a aposentadoria ambivalência quanto a ser ou não policial. O que significa não ser mais policial? É somente deixar os instrumentos de trabalho, os colegas, o meio profissional? Ou é se desligar do juramento feito no momento solene da posse, de tudo o que acreditou e defendeu durante a vida profissional? E a sociedade, como percebe este ex-policial? Esses questionamentos convidam a refletir sobre a importância da identidade profissional para essas pessoas, que muito vezes encontram-se num dilema entre o que foram grande parte da vida adulta e o que serão a partir de agora. Um professor aposentado pode eventualmente continuar a lecionar; um médico aposentado sempre terá a opção de voltar à clínica; e o policial?

Quanto ao resultado da auto-avaliação, ficou registrada a satisfação do grupo em ter participado deste primeiro Programa de Preparação para Aposentadoria, sendo considerado um dos pontos mais relevantes, a possibilidade de falar de si mesmo, situação essa pouco vivenciada até então. Destaca-se que os participantes foram unânimes em agradecer ao seu sindicato por oferecer tal programa, que teve com objetivo principal orientar os policiais para que façam uma transição melhor entre o emprego e a aposentadoria.

Evidencia-se a importância da realização de pesquisas preliminares em grupos de PPA (ZANELLI; SILVA, 1996), ou seja, a relevância da elaboração de diagnósticos prévios (FRANÇA, 2008). Não obstante a dimensão social da aposentadoria, ela é um processo que se configura de acordo com as especi- 
ficidades de determinados grupos e indivíduos. Conhecer os participantes dos grupos de PPA e a realidade por eles vivenciada fornece condições para a construção de métodos e técnicas específicas para suas necessidades.

Diante disto, o Programa desenvolvido com Policiais Federais levou em consideração sua faixa etária, as características do seu vínculo com a profissão (rotina de trabalho dinâmica, deveres profissionais em tempo integral, estabilidade e rigidez disciplinar nas relações de trabalho), questões de gênero (predominantemente masculino) e seu nível de renda (acima da média da população brasileira). Os procedimentos adotados, bem como os resultados alcançados, não podem, assim, ser generalizados para grupos com características marcadamente distintas. Existem diferenças no processo de significação e enfrentamento dessa etapa de vida de acordo com fatores pessoais, culturais, sociais e econômicos a que estão submetidos os trabalhadores (RODRIGUES et al., 2005).

Por fim, percebe-se a relevância da intervenção de Psicólogos no planejamento e execução de PPAs, para auxiliar as pessoas que estão atravessando essa fase de transição, repleta de dúvidas e incertezas. Um dos grandes desafios para os profissionais parece ser descobrir, enquanto estão na ativa, outras fontes de prazer e realização para além do trabalho/emprego. Por isso, acredita-se na importância do desenvolvimento de Programas de Preparação para Aposentadoria com diferentes categorias de trabalhadores, com destaque para as que envolvem intensamente os profissionais.

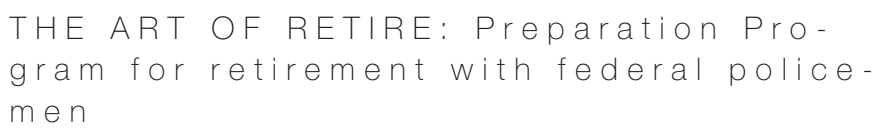

abstract

The advancement of science and technology has taken a progressive increase in longevity and life expectancy, letting people enjoy a longer period of their existence as a retiree still enjoying good physical and mental conditions. Therefore, this article presents reflections on the theme of retirement, based on the report of a Retirement Preparation Program (PPA) developed with Federal Policemen. This Program was conducted in three meetings, eight hours each one, and characterized by approaching the topic in an experiential way, using specific techniques to work themes such as life projects and professional reorientation considering the different aspects that permeate 
this time of change (health, leisure, finance, spirituality, family, etc.). It was found in theory and in practice that the retirement process of the Federal Policemen involves specific changes that require family, emotional and socialreorganization, which highlights the importance of developing programs to work these aspects.

keywords

Retirement. Preparation Program for retirement. Federal Policemen.

\section{referências}

BEAKLINI, Bruno Lima Rocha. A Polícia Federal após a Constituição de 1988: polícia de governo, segurança de Estado e polícia judiciária. 2004. 248 f. Dissertação (mestrado em Ciências Políticas) - Universidade Federal do Rio Grande do Sul- Porto Alegre, 2004.

BRASIL. Decreto-Lei no3689 de 3 de outubro de 1941. Código de Processo Penal, art.301.

CABEZA, Manuel Cuenca. Más Allá Del trabajo: El ócio de los jubilados / Beyond work: leisure of the retired. Revista Mal-estar e subjetividade, Fortaleza, v. 9, p 13-42, 2009.

CARLOS, Sergio Antônio et al. Identidade, Aposentadoria e Terceira Idade. Estudos interdisciplinares sobre Envelhecimento, Porto Alegre, v. 1, p. 77-88, 1999.

DEPARTAMENTO DE POLÍCIA FEDERAL. Livro de Comemoração dos 60 anos da Polícia Federal. Brasília: DPF, 2004.

ELY, Fabiana Regina. O super-herói (nem tanto) também adoece: Um estudo em saúde do trabalhador com servidores da Polícia Federal em SC. 2002. 105 f. Dissertação (em Serviço Social) do programa de Pós Graduação em Serviço Social - Universidade Federal de Santa Catarina-Florianópolis. 2007.

FRANÇA, Lucia. O desafio da aposentadoria. Rio de Janeiro: Rocco, 2008.

FRIGOTTO, Gaudêncio. A dupla face do trabalho: criação e destruição da vida. in: FRIGOTTO, G.; CIAVATTA, M. (Orgs.) A experiência do trabalho e a educação básica. Rio do Janeiro, RJ: DP\&A, 2002, p. 11-27.

INSTITUTO BRASILEIRO DE GEOGRAFIA E ESTATÍSTICA - IBGE. Banco de Dados Agregados. Sistema IBGE de Recuperação Automática - SIDRA. Recuperado em 28 de setembro, 2008: Em: http://www.ibge.gov.br/ibgeteen/datas/idoso/preocupacao_futura.html

LAFFIN, Marcos. De contador a professor - a trajetória da docência no ensino superior de contabilidade. 2002. 271 f. Tese (Doutorado em Engenharia de Produção) - Universidade Federal de Santa Catarina, Florianópolis. 2002.

LEI COMPLEMENTAR № 51, DE 20 DE DEZEMBRO DE 1985. Dispõe sobre a aposentadoria do funcionário policial, nos termos do art. 103, da Constituição Federal. Recuperado em 26 de março de 2010. Em: http://wnw.jurisway.org.br

LIMA, Marilaine Bittencourt de Freitas. Aposentadoria: fim ou recomeço? Percepção de professores aposentados sobre a influência da aposentadoria nas suas trajetórias profissionais e nos seus estilos de vida. 2006. 78f. Trabalho de conclusão de curso (graduação em Psicologia) - Universidade do Sul de Santa Catarina, Palhoça. 2006.

LUCCHIARI-SOARES, Dulce Helena Penna. Pensando e Vivendo a Orientação Profissional. São Paulo: Summus, 1992. 
LUNA, lúri Novaes; BAPTISTA, Lavínia Costa. Identidade profissional: prazer e sofrimento no mundo do trabalho. Psicologia Revista, São Paulo, v. 12, n. 1, p. 39-51, maio 2001.

MOSCOVICl, Fela. Renascença Organizacional: a revalorização do homem frente à tecnologia para o sucesso da nova empresa. São Paulo: José Olympio, 2000.

RODRIGUES, Milena et al. A preparação para a aposentadoria: o papel do psicólogo frente a essa questão. Revista Brasileira de Orientação Profissional, São Paulo, v. 6, n. 1, p. 53-62, 2005

SINGER, Paul. Globalização e desemprego: diagnóstico e alternativas. 4. ed. São Paulo: Contexto, 2003.

SOARES, Dulce Helena Penna et al. Aposenta-ação: programa de preparação para aposentadoria. Estudos Interdisciplinares sobre Envelhecimento, Porto Alegre, v. 12, p. $143-161,2007$

SOARES, Dulce Helena Penna; COSTA, Aline Bogoni. Projeto de futuro na aposentadoria: uma discussão fundamentada pela orientação profissional em psicologia. Revista Perspectivas en Psicología y Ciencias Afines, Buenos Aires, v. 5, p. 37-46, 2008.

SOARES, Dulce Helena Penna et al. Técnica: Trevo de Quatro folhas da aposentadoria. In: II CONGRESSO LATINO-AMERICANO DE ORIENTAÇÃO PROFISSIONAL, resUmo de painéis, 2009, São Paulo. p. 97-98. Disponível em: <http://abopbrasil.org.br/ arqs/581 congresso.pdf>. Acesso em: 05 jan. 2009

SOARES, Dulce Helena Penna. A escolha profissional do jovem ao adulto. São Paulo: Summus, 2002.

TOLFO, Suzana da Rosa; SILVA, Narbal; LUNA, lúri Novaes. Cultura organizacional, identidade e qualidade de vida no trabalho: articulações e sugestões de pesquisas em organizações. Pesquisas e Práticas Psicossociais, São João del-Rei, v. 4, n.1, p. 6-16, Dez. 2009.

UNIVERSIDADE FEDERAL DE SANTA CATARINA; INSTITUTO SAÚDE E PRODUTIVIDADE. I Congresso Brasileiro de Orientação para Aposentadoria nas Organizações. Disponível em: < http://www.aposentadoriacongresso.com.br/index.php>. Acesso em: 06 jun. 2010.

ZANELLI, José Carlos; SILVA, Narbal; SOARES, Dulce Helena Penna. Orientação para aposentadoria nas organizações de trabalho: construção de projetos para o pós-carreira. Porto Alegre: Artmed, 2010.

ZANELLI, José Carlos; SILVA, Narbal. Programa de Preparação para a Aposentadoria. Florianópolis: Insular, 1996.

1) O que sentia quando PARTICIPAVA DOS ENCONTROS:

Síntese: expectativa, curiosidade, interesse no depoimento dos colegas, realização e comprometimento. "Sensação de participar de algo instigante e gratificante".

2) O que sentia quando REALIZAVA AS TAREFAS SOLICITADAS:

Síntese: emoção, alegria e entusiasmo. "Alegria de estar reunido com os colegas".

3) Antes de iniciar o programa de preparação para aposentadoria EU ME SENTIA:

Síntese: indeciso, apreensivo, curioso e desconfiado. "Quase preparado para me aposentar".

Agora ESTOU ME SENTINDO:

Síntese: tranquilo, seguro da decisão de aposentar-se e com perspectivas futuras. "Estou convencido de que a aposentadoria é um prêmio e que eu sou merecedor deste". 
(continuação)

4) O Programa de Aposentadoria ME AUXILIOU NOS SEGUINTES PONTOS:

Síntese: reflexão sobre o passado e perspectivas futuras, melhor entendimento da aposentado-

ria e da vida em grupo. "Entendi que nos aposentamos do emprego e não do trabalho; também

cheguei à conclusão de que a vida em grupo é muito importante".

O Programa de Aposentadoria NÃO ME AUXILIOU NOS SEGUINTES PONTOS:

Síntese: O curso atingiu todos os pontos propostos inicialmente. "Nada a reclamar, pois em todos os pontos aprendi algo de bom e interessante".

5) Quais as atividades que MAIS GOSTEl?

Síntese: debates, projetos de futuros, técnica da agenda e mandala. "A mandala, porque efetivamente ela registra no papel o que foi discutido durante o curso; a técnica da agenda também pelo registro documental; objetivo, pois nos auxiliou no planejamento não só da aposentadoria, mas também da vida".

Quais as atividades que MENOS GOSTEl?

Síntese: não foi identificada nenhuma atividade que tenha gostado menos. "Gostei de todas as atividades".

6) O que sentia quanto ao TIPO DE TRABALHO PROPOSTO?

Síntese: curiosidade, interesse e satisfação. "Aguçou o questionamento e proporcionou a exposição de fatos, situações e ideais...".

O que sentia quanto ao FATO DE SER EM GRUPO?

Síntese: provocativo, estimulante e satisfatório. "Foi muito instigante pela troca de experiência".

\section{7) SUGESTÕES E CRITTICAS:}

Realização de programas anuais e com maior número de participantes. "Procurar sempre aperfeiçoamento profissional nessa área de aposentadoria e que ajudem na formação de outros".

8) Você acha que O SINDICATO DEVE CONTINUAR SE RESPONSABILIZANDO POR ESTE PROGRAMA?

Síntese: para alguns, sim. "Sim, o Sindicato deve estar sempre atento ao bem-estar do sindicalizado e a aposentadoria faz parte da trajetória desse bem-estar."

Para outros, a administração da Policial Federal deveria se responsabilizar pelo Programa. "Entendo que a iniciativa do Sindicato foi louvável, mas esse trabalho deveria ser um dos objetivos, logo a responsabilidade deveria ser do órgão, e voltado para todos os servidores às vésperas da aposentadoria."

Quadro 1-Questões da ficha de avaliação com síntese das respostas

Recebido: 07/04/2010

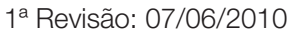

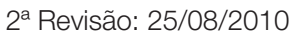

Aceite Final: 31/08/2010 